\title{
Organizational Coordination Theory and Its Application in Virtual Enterprise
}

\author{
Xiuquan Deng, Tong Chen and Dongdi Pan \\ School of Economics and Management, Beihang University, Beijing 100083, P.R. China \\ dengxiuquan@126.com chting714@gmail.com
}

\begin{abstract}
As one of the most important theories, coordination appears in a lot of fields and becomes a remarkable subject. This paper sums up the frame of the organizational coordination theory by refining the meaning of coordination, and with the support of this frame, studies the virtual enterprise's coordination mechanism in two layers which are the strategy layer and the task layer according to the characteristic of the dependences among the member companies. In the strategy layer, the trust relation in the virtual enterprise is built to coordinate the member companies' cooperating relations. And in the task layer, the task is decomposed and coordinated smoothly to make sure the achievement of the virtual enterprise's aim.
\end{abstract}

Keywords: Organizational coordination theory, Virtual enterprise, Coordination mechanism, Trust mechanism, Resource estimation

In the process of organization activities, coordination is a very widespread problem. Because of the large volume of communication, coordination is considered a very great need to virtual organization.

\section{ORGANIZATIONAL COORDINATION THEORY}

Coordination is the behavior that manages the interdependent relationships of activities with common object; the coordination mechanism is the mechanism that manages the dependent relationship effectively [1]. According to this definition, coordination contains two fields of knowledge: knowledge of the activity interdependences and knowledge of managing the independent relationship (the management performs as coordination mechanism) [2].

The study of organizational coordination theory should include the organizational dependence, coordination mechanisms and the factors affect its establishment (technical, structural and organizational task types) [3]. 


\section{VIRTUAL ENTERPRISE COORDINATION MECHANISM}

\subsection{The Essence of Virtual Enterprise}

Virtual Enterprise is opposed to the traditional enterprises. Its substance is that member enterprises operate with outside helps, integrating the external resources, achieving the function that they do not have and creating a powerful competitive advantage. In cooperation way, member enterprises can achieve functions such as research, development, production, sales and marketing, and other specific functions.

\subsection{The Constitution of Virtual enterprises Coordination Mechanism}

In this paper, the so-called virtual enterprises coordination mechanism refers to ways and means that the virtual enterprise members use to make normal communication and coordination, thus to achieve the coordination between all members of enterprises. In order to study the virtual Enterprise coordination mechanism, we must study the interdependent relationship between the virtual enterprise members. So far, there is not a recognized classification to it. According to the formation and operation process of virtual enterprise, we should class the dependence into levels: confidence dependent relationship on strategic level, and activity dependent relation on task level. (See Figure.1)

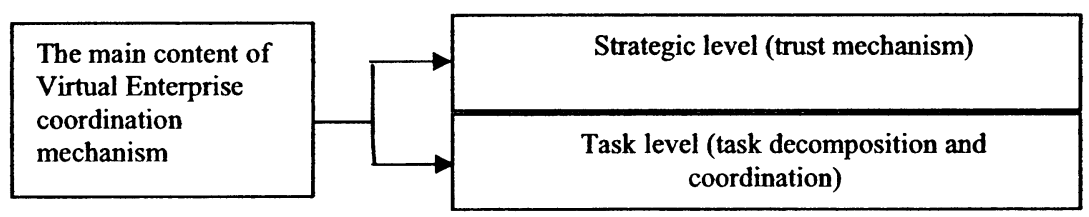

\section{Figure 1. Virtual Enterprise Coordination Mechanism System Map}

\subsection{Virtual Enterprise Strategic Level Coordination}

We class the confidence dependent relationship, taking the establishment and development of the confidence relationship as the basis for demarcation, considering about the time dimension, as follows: the initial trust and the continual trust.

The so-called initial trust is the trust relationship forms in the gestation period and the formation period of virtual enterprise. Initial trust may be just established relations or a continuation of former cooperation or transferred from the third party. Its biggest feature is the complication of the relationship. The so-called continual trust is the trust relationship forms in the operation period or the disintegration period. Continual trust is dynamic developed relations. Generally speaking, the level is higher, but it does not 
rule out the trust of low level and even the breakdown of a trust relationship caused by the opportunistic behaviors of cooperation partner.

With the virtual enterprise creation, growth, maturity, disintegration and reorganization, Virtual Enterprise's relationship of trust constitutes a "chain of trust": the initial trust- $>$ continual confidence- $>$ initial trust.

There are two kinds of trust relationship modes fit the characteristics of Virtual Enterprise: relation-based market model and credibility model [4].

The so-called relation-based market model is the model that member enterprises invest in specific field via their respective relation-network to build up mutual trust. However, the specificity of the trust investment is always strong; the cost of conversion is high or even cannot change. When cooperation between the members is made a temporary suspension, these investments will have difficulty in using for other purposes, which may cause excessive dependence of one member on the other or substantial control. Thereby it limits the establishment of a trust relationship in virtual enterprise and the flexibility of development. Meanwhile, the trust relationship based on the "personal relationship circles" is relatively fragile; the bad behaviors of some individual enterprises can easily destabilize the entire virtual enterprise.

The credibility model is the model that the virtual enterprise via the establishment of a mechanism to build and maintain a trust relationship. Corporate credibility is the comprehensive evaluation, gained in the business activities, on the capacity, efficiency, business philosophy and corporate culture, and other aspects. Corporate credibility can be conveyed by the market, supported by legal and moral, its formation needs a long-term accumulation, having greater stability.

The confidence in virtual Enterprise is uncertainty-and-risk-related; consequently, to increase the credibility, it is necessary to make security measures.

In a virtual enterprise which members have different interest objectives, it is necessary to consider the balance of interests and the establishment of an effective incentive system or mechanism. Meanwhile, a fair distribution of benefits can also bound the deception of partners.

\subsection{Virtual Enterprise Task Level Coordination}

Members in virtual enterprise generally use or consume some of the logistics resources in the activities of implementation process, particularly exclusive resources; the dependent relationship of member enterprises can be divided into three categories: 1-1-dependence, $\mathrm{N}$-1-dependence and 1-N-dependence.

Because virtual enterprise is composed of members with same geographical distribution, but different self-interests, so the characteristic of incomplete information, as well as the powerless control to members is prominent, thus the task decomposition of virtual enterprise compared to the individual enterprises is more difficult, it needs a task decomposition method as a guide which can adapt to the characteristics of virtual enterprise.

Members of virtual Enterprise need task coordination, the basic idea is as follows(See Figure.2): The first step is the core enterprise to find market opportunities, as well as analysis for market opportunities to determine each sub-task required resources (including core competencies); The second step is based on the capacity-demand information to identify potential partners, choose the partners who 
are competent for the sub-tasks; The third step is to allocate the tasks to member enterprises, member enterprises provide a detailed production plan in accordance with the requirements of sub-tasks and submit its conclusions back to the core enterprise; The fourth step, the core enterprise make optimization, integration, modification to the sub-enterprises' programs, and then revise the results to member enterprises; The fifth step, member enterprises consider the feedback and analyze whether they have the ability and quality to timely complete the volume of production. If the capacity allows, task decomposition and the process of planning coordinating ended, and the members sign the contract of sub-tasks; or consulate with the core enterprise, if succeeded, the task decomposition process and plan coordination accomplish; if the negotiation failed, the core enterprise look for new cooperating partners.

\section{CONCLUSIONS}

Being a key management method for the formation and operation of virtual enterprise, Coordination theory has an important impact on the results that the virtual enterprise achieved in the production and operation process. In this paper, the results of the study are expected to design an appropriate coordination mechanism for virtual enterprises, thus the members of virtual enterprise can establish strategic cooperative partnership, then rationally distribute the profits, share risks, improve information sharing, reduce inventory, lower total system cost and eventually realize the profit maximization.

\section{EMPIRICAL ANALYSIS}

About the empirical analysis, we have already made preliminary work, but because of limited space, it is not showed here. 


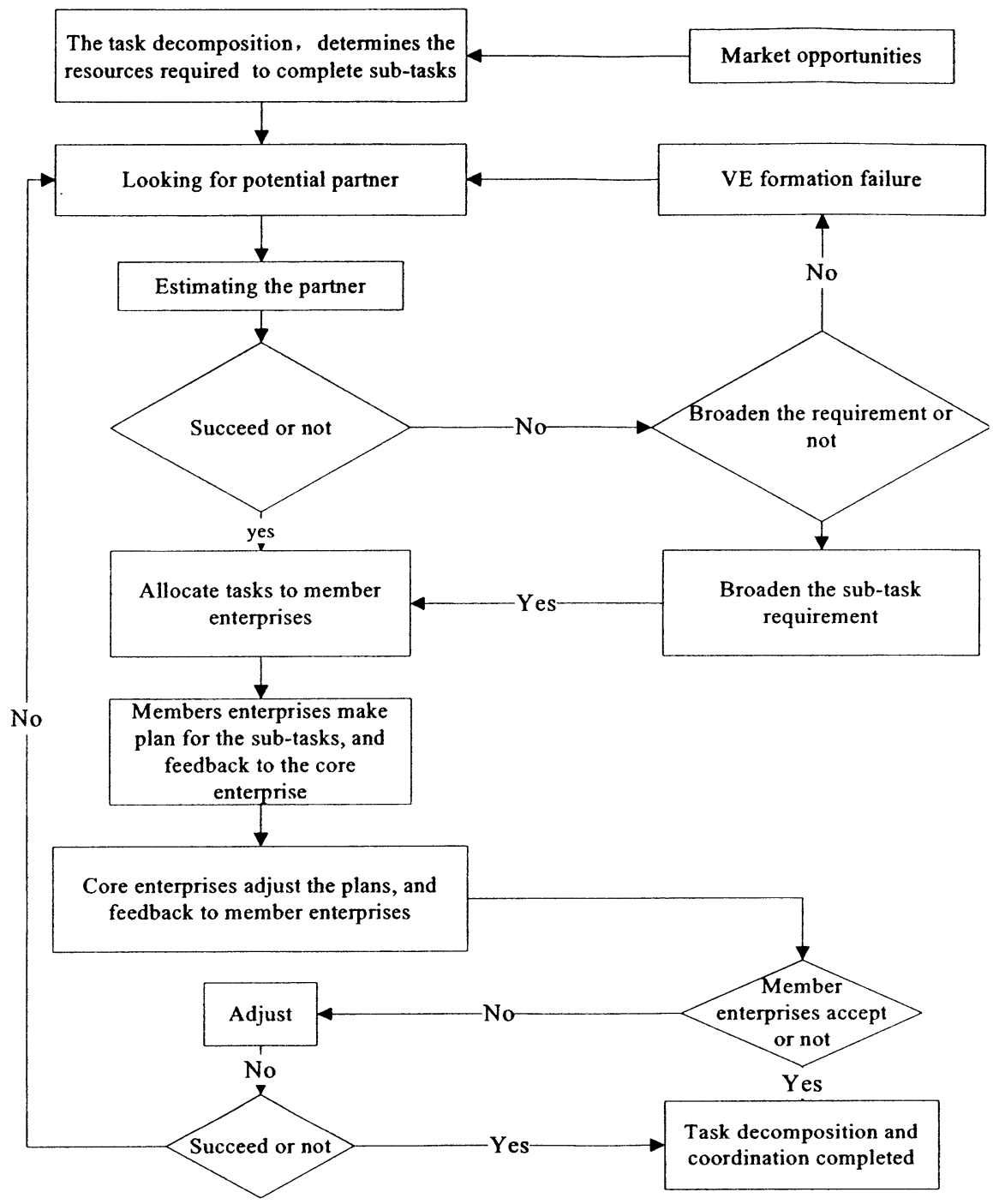

Figure 2. The Basic Ideas of Virtual Enterprise Task Decomposition and Coordination

\section{ACKNOWLEDGMENT}

This paper was supported by the grants from Aviation Science Foundation of China (No.2006ZG51080) and BUAA "New Star in Blue Sky" Plan. 


\section{REFERENCES}

1. T.W. Malone and $\mathrm{K}$. Crowston, The interdisciplinary study of coordination, $A C M$ Computing Surveys. Volume 26, Number 1, pp.87-119, (1994).

2. T.W. Malone, and K. Crowston. Tools for inventing organizations: toward a handbook of organizational processes, Management Science. Volume 45, Number 3, pp.425-443, (1999).

3. H. Jing and Y. Xi. Retrospect and Prospect to Organizational Coordination theoretical research, Management Review. Volume 18, Number 2, pp.50-55, (2006).

4. M. Granovetter, Economic action and social structure: the problem of embeddedness, American Journal of Sociology. Volume 91, pp.481-510, (1985).

5. $\mathrm{K}$. Crowston, A Taxonomy of Organizational Dependencies and Coordination Mechanisms (1994). http://ccs.mit.edu/tom.html 